OPEN ACCESS

Edited by:

Kilian Spandler,

University of Gothenburg, Sweden

Reviewed by: Catherine Baillie Abidi, Dalhousie University, Canada Kaarina Nikunen,

Tampere University, Finland

${ }^{*}$ Correspondence: Lee Michael Shults lee.m.shults@uia.no

Specialty section: This article was submitted to Refugees and Conflict, a section of the journal Frontiers in Political Science

Received: 04 April 2021 Accepted: 27 May 2021 Published: 20 July 2021

Citation:

Shults $L M$, Haaland $H$ and Wallevik $H$ (2021) Localizing Global Solidarity:

Humanitarian Aid in Lesvos.

Front. Polit. Sci. 3:690907. doi: 10.3389/fpos.2021.690907

\section{Localizing Global Solidarity: Humanitarian Aid in Lesvos}

\author{
Lee Michael Shults *, Hanne Haaland and Hege Wallevik \\ Department of Global Development Studies and Social Planning, University of Agder, Kristiansand, Norway
}

The so-called "refugee crisis" in Lesvos, Greece provides a poignant example of situated, local suffering that has called for the coordination of global resources to provide relief. Some of the first to respond were local and international Citizen Initiatives for Global Solidarity (CIGS). While a growing role for CIGS has been interpreted as a call for more global involvement, arguments for the increased localization of relief efforts suggest the need for aid agents to maintain a reflexive awareness of the potential for an influx of outside assistance to disempower those most affected. We argue that barriers to implementing the localization of humanitarian aid can be better understood by positioning this localization alongside theories of global solidarity. This paper pairs theoretical contributions from the fields of moral and political philosophy with an analysis of interview material gathered in Lesvos between 2015 and 2019. Our goal is to use narratives of conflicting interests in Lesvos to explore conceptual distinctions concerning solidarity and emphasize the importance of the localization of global solidarity in humanitarian aid. We conclude that while global solidarity represents a demanding effort to identify with distant others and provide aid, the intensity and transformative potential of the process of "making the crisis one's own" through solidary engagement can overshadow the importance of local ownership of crisis management.

Keywords: ethics of solidarity, politics of aid, CIGS, refugee "crisis" humanitarianism, Lesvos, local empowerment

\section{INTRODUCTION AND BACKGROUND}

Citizen Initiatives for Global Solidarity (CIGS) play a unique role in humanitarian aid, which has been previously explored in the context of Lesvos (Haaland and Wallevik, 2019). These small, unofficial, and unstructured personalized aid projects "pop-up" to meet emergent needs and acute crises (Schulpen and Huyse, 2017, 163). While CIGS are not new, they are becoming increasingly recognized as influential aid actors (Fechter and Schwittay, 2019). Due to their flexible character, CIGS can address unmet needs as service providers or as watchdogs for traditional aid organizations. While some CIGS are short-lived, others maintain a strong presence over time, occasionally evolving into larger NGOs in order to gain access to the resources offered by established humanitarian networks (Oikonomakis, 2018, 72). The abilities of CIGS to adapt and mobilize rapidly have challenged established conceptions of aid governance, project sustainability, and efficiency of resource allocation.

In 2015, CIGS were among the earliest responders to the unexpected arrival of thousands of refugees travelling across the Aegean Sea from Turkey to Lesvos. The geographical position of the island quickly transformed Lesvos into the "epicenter of what is known as the 'European refugee crisis"' (Rozakou, 2017, 102). The island was not prepared to handle a refugee crisis of this scale, especially while simultaneously struggling with the lasting effects of the 2008 financial crisis, high 
levels of unemployment, and capital controls that had been recently imposed on the Greek banking system. However, despite these challenges, the island community of Lesvos attracted positive international attention for welcoming the refugees with open arms at the start of the crisis (Cantat 2018, 8).

Particularly in the first months of the crisis, local initiatives and international CIGS bore a great deal of responsibility for crisis management, as the mobilization of the more established humanitarian aid "machinery" took time. The absence of established national and international actors at the beginning of the crisis led to a "mistrust of government and institutionalized charity" (Witcher, 2020, 5) among CIGS and other communitybased organizations. The anti-hierarchical resistance that many CIGS displayed towards traditional, coordinated crisis management has been interpreted as a critique of holes in the international response to the humanitarian crisis, and as a demand for an increase in "global acts of responsibility and solidarity" that might "enable us to think beyond the management of crisis locally" (Haaland and Wallevik, 2019, 1880). This paper builds on that analysis by connecting aspects of competing theories of global solidarity to efforts towards the localization of humanitarian aid, drawing on empirical data gathered in Lesvos between 2015 and 2019. As such, this article represents an attempt to bridge philosophical approaches to the concept of solidarity and social scientific research on the localization of humanitarian aid and the evolving role of CIGS.

While there may appear to be a prima facie tension between increased global solidarity and increased localization of aid; existing research on solidarity in Greece has already connected empowerment through locally run, redistributive efforts to the potential of these "bottom-up" initiatives to critique and alter national and international politics (Rakopoulos, 2014; Arampatzi, 2017). While the desirability of local empowerment remains uncontroversial, the type of networked solidarity required to provide aid in times of crisis has an unavoidable global or international element as well. By addressing conceptual distinctions and empirically informed connections between global solidarity and the localization of humanitarian aid, this paper aims to point to informative tensions and productive similarities between these efforts.

The phrases "global solidarity" and "localization of humanitarian aid" share two important traits. First, they have progressive and inclusive connotations, sharing near unanimous support at an abstract level. Second, attempts to implement these broad concepts in practical situations often prove controversial and complicated. We argue that these difficulties stem partially from the fact that the meanings of these terms must be determined case by case and contextually redefined as existing needs are met or reinterpreted, and new needs emerge.

Killian Spandler describes the localization of humanitarian aid as a matter of facilitating "more ownership for state and non-state actors in close proximity to the emergencies" $(2020,2)$. The challenge of applying this definition at a practical level involves negotiating competing understandings of proximity. Using the influx of refugees in Lesvos as an example: the local government, the citizens of Lesvos, local initiatives, and the refugees themselves all have radically different ideas about who needs aid and how it should be provided. Each could make legitimate claims to proximity to the emergency. Further complicating the situation, none of these groups are homogenous in terms of perspectives or goals. If it were decided that, in the interests of local empowerment, the citizens of Lesvos should have more ownership over the coordination of humanitarian aid efforts-the process of providing a representative system with a sufficiently unified agenda for achieving this goal would be daunting, if not impossible.

There are clear parallels between the challenge of determining which groups have a relevant sense of proximity to a humanitarian crisis and the challenge of coordinating overlapping efforts towards global solidarity in response to a crisis. Before confronting several existing treatments of global solidarity, it is important to offer a clear distinction between what we refer to in this paper as local solidarity and global solidarity. Local solidarity is understood here as representing a willingness to act in the interests of one's established in-groups, while global solidarity represents a willingness to act in the interests of distant out-groups. The relevant factors that constitute distance between groups vary contextually - much like relevant senses of proximity in the example above. Acknowledging group membership when distinguishing between types of solidarity is critical in avoiding the pitfalls of colonialism and paternalism that too often plague international humanitarian aid (Spandler, 2020, 6).

Locals in Lesvos are distinctly aware of the potential dangers of these power dynamics, with one of our interview participants explicitly referring to NGOs as "colonizers" (Ilhias, man 40 years., 2016) ${ }^{1}$. A skepticism towards "the neocolonial attitude of international humanitarian actors" (Rozakou, 2017, 102) is confirmed by other ethnographic studies of Lesvos. While there is a rich literature connecting this skepticism to group identity and the development of the refugee crisis in Greece, existing research primarily treats solidarity as a characteristic of local initiatives and traces the historical and linguistic significance of solidarity in Greek culture to its current humanitarian expressions (Rozakou, 2016b; Arampatzi, 2017; Serntedakis, 2017). In distinguishing between local and global solidarity, this paper represents an important step towards addressing the "conceptual imprecision ... reproduced by the coexistence of the concepts 'solidarity' and 'humanitarianism' in the same conversations" (Theodossopoulos, 2016, 170).

The emphasis on incorporating global solidarity into the ongoing discussion of humanitarian aid and crisis management in Lesvos, is connected to our choice of the term CIGS. While other treatments of solidarity with refugees have used terms such as citizens' initiatives (Rozakou, 2016b, 81), solidarity initiatives (Daskalaki and Kokkinidis, 2017, 1305), and refugee solidarity movements (Oikonomakis, 2018, 66) to describe various egalitarian, ad hoc, efforts to offer material or relational support-a designation that includes global solidarity highlights a crucial, relational orientation towards the mediation of distance between one's established in-groups and marginalized

${ }^{1}$ All names of interview participants used in this paper are fictive. 
out-groups. We argue that if the concept of global solidarity is to provide insights into the dynamics of localization and empowerment, the social and structural relations of the agents involved must be recognized. Differentiating between the local and the global in terms of group membership serves as a reminder that, even when working together in solidarity, the motivations and obligations of outsiders providing aid both stem from and generate different normative commitments than those of locals.

Expanding on this distinction, section two begins by outlining and contrasting the accounts of the motivation of global solidarity offered by Richard Rorty and Avery Kolers. While an exhaustive review of the relevant philosophical literature on global solidarity is beyond the scope of this paper, these two theories provide clear examples of positions at opposing sides of the sentimentalist-rationalist spectrum of motivation. The emphasis of motivation in accounting for global solidarity is then problematized by an interpretation of the work of Amanda Taylor. Using the theoretical framework developed in section two, sections three and four explore the contextual tensions and intergroup dynamics observed during field work in Lesvos. Section five synthesizes critical reflections from the previous sections and suggests a productive interplay between global solidarity and the localization of humanitarian aid, that we argue renders the two compatible.

\section{THEORETICAL FRAMEWORK}

If the role of CIGS is to be meaningfully discussed in terms of calling for-or practically representing-a novel sense of global solidarity, conceptual clarity will be crucial. Existing conceptualizations of global solidarity generally fall into one of two camps, which have been referred to as sentimentalist and rationalist (Sandelind and Ulaş, 2020, 564; Lenard et al., 2010, 101). The distinction between a relational ethics of care on the one hand, and rational political engagement on the other, is common to analyses of solidarity and humanitarianism alike (Bauder and Juffs, 2020, 10). While the terminology varies from theory to theory, we argue that both sentimentalist and rationalist approaches are compatible with the distinction we have offered between local and global solidarities. A perennial problem for both sentimentalists and rationalists, which is especially relevant to humanitarian crises, concerns the difficulties of motivating global solidarity with distant others (Lenard, 2010; Chouliaraki, 2013; Gould, 2020). Upon hearing that a neighbor is suddenly without a place to stay, it may feel natural to provide support even at the expense of one's own comfort and lifestyle. However, upon hearing that there are refugees without shelter in another country, involvement may not come as naturally and one's role may not be as immediately clear. We turn now to examples of sentimentalist and rationalist treatments of motivating global solidarity, before considering whether or not the very emphasis of motivation is problematic when balancing global solidarity and the localization of humanitarian aid.

\section{Richard Rorty, Ethnocentrism, and Sentimental Education}

Sentimentalist approaches to the challenge of motivating global solidarity emphasize the potential for particular individuals or communities to be inspired to offer support to particular distant others in specific contexts. Affective elements are often underlined, describing the global component of global solidarity as a matter of increasing inclusivity (Rorty, 1989), extending social empathy (Gould, 2007), or broadening the redistribution of relational goods (Straehle, 2020). Particular local commitments based on fellow feeling and sentimentality are seen as potentially unproblematic, or even as the best available tools to facilitate moral progress towards a global solidarity that is grounded in care and trust (Baier, 1991).

The work of Richard Rorty offers one of the most influential contributions to a sentimentalist conceptualization of global solidarity. Rorty argues that moral progress towards greater global solidarity is a matter of increasing ethnocentric inclusivity (Rorty, 1991, 1:30). Rorty's unconventional use of the term ethnocentrism is an expression of his conviction that one cannot climb outside of one's own situated position to make an agent-neutral or theory-neutral evaluation of any context. Being ethnocentric in a Rortyan sense, means acknowledging that new interpretations of one's moral obligations must be weighed against existing interpretations, rather than against whatever might be assumed to provide a neutral background for an impartial choice. Efforts towards ethnocentric inclusivity aim to extend or shift existing local solidarities to distant, suffering out-groups. On this view, an acute humanitarian crisis can be interpreted as a moral reason to engage and support distant others as one would if the crisis were causing harm to one's local in-groups.

Effectively motivating global solidarity, on a Rortyan account, hinges upon the development of "the ability to see more and more traditional differences (of tribe, religion, race, customs, and the like) as unimportant ... the ability to think of people wildly different from ourselves as included in the range of 'us"' (1989, 192). Increasing this ability to dismiss the distance between "us" and these "wildly different others," relies on an understanding of self-creation as redescription rather than transcendence. Rorty's proposal to develop attitudes of global solidarity through ethnocentric, inclusive redescriptions suggests that motivating actions in support of a distant refugee crisis is a matter of describing the situations of those with proximity to the crisis in ways that allow one to identify this distant problem as one's own. An ethnocentric approach to redescription favors an openness to empathic "world-travelling" over static commitments to all members of the species (Lugones, 1987). Sandra Lee Bartky refers to this openness as a rejection of attempts to achieve "a view from nowhere", in favor of attempts to gain "a view from somewhere different" (Bartky, 1998, 387).

Rorty refers to self-creation through attempts to sensitize oneself to distant problems, and identify with distant others, as a process of sentimental education (Rorty, 1998, 3:176). Motivating global solidarity through sentimental education is a 
matter of increasing global sensitivity to narratives of suffering. For Rorty, this sensitivity is most easily achieved through "the continual refreshment and re-creation of the self, through interaction with selves as unlike itself as possible" (1998, 3: 183). Thus, while the situated perspectives of the individuals involved in global solidarity relations are unavoidable, and while complete agent-neutrality or impartiality is unobtainable, there remains an opportunity to "gain more critical leverage the more we experience and expose ourselves to others' standpoints" (Thayer-Bacon, 2010, 10). This strategy parallels a conclusion drawn from previous research into the motivations of CIGS, namely that "for many their involvement must also be understood as a project of self-construction and identity. The helping of others contributes to the construction of self' (Haaland and Wallevik, 2017, 206). A similar conclusion was reached regarding Finnish citizens' involvement in international development projects (Malkki, 2015).

An interpretation of global solidarity as sentimental education and self-creation is supported by the affective and personal components of motivation shared in the following narrative from a CIGS member in Lesvos:

"I've been kind of monitoring the situation with the crisis and I'm quite passionate about it. I'm not an activist at all, because I'm a bit more calmer and just want everybody to be full of love and life to be honest. (Laughter) And I don't get caught up in politics ... And then I just realized ... This is my opportunity to take a bit of a career break." (Crystal, woman 30 years., 2016)

Here we see identification with the refugee crisis described in affective terms of passion and a desire to spread love and life, rather than in terms of political activism. This narrative offers an example of global solidarity inspired by sentiment, which offers both transformative interactions with distant others and a deviation from an established career path. Interestingly, this woman's previous career experience was connected to humanitarian aid. When asked about the professionalizing influence that she described her involvement having on the initiative, she described this influence as unfortunate, saying:

"I didn't want to tap into too many of my previous skills. Because it made me feel like I was doing something from before." (ibid.)

The transformative power of acting in global solidarity and the appeal of self-creation through active and empathic identification with others should not be underestimated as a motivator of humanitarian aid.

In some instances, those motivated by a more "ethnocentric" and sentimental approach are considered too individualistic, engaged in something very different from solidarity (Serntedakis, 2017, 91). Importantly, this potential criticism should not be limited to international volunteers, as Theodossopoulos connects "the empowering dimension of solidarity" and "the emancipatory euphoria of their participatory experience" to opportunities for local Greeks "to escape temporarily from the paralyzing, disempowering effects of austerity" by engaging refugees $(2016,176)$. This serves as a reminder of the importance of conceptual clarity regarding global solidarity and local empowerment. If global and local solidarities are differentiated using group membership, the global solidarity demonstrated by the citizens of Lesvos can be an integral part of local empowerment. On the other hand, ethnocentric and sentimentally motivated solidarity runs the risk of prioritizing self-creation or personal transformation over the needs of the supposed recipients of solidarity support and can depoliticize the structural causes of humanitarian crises (Ticktin, 2014, 283).

From a Rortyan perspective, those who find personal and emotional motivations problematic would do well to discard the "opposition between self-interest and morality, an opposition which makes it hard to realize that my pride in being a part of the human rights culture is no more external to myself than my desire for financial or sexual success" (1998, 3:176). Here Rorty presents moral obligation as made, rather than found. This would suggest, unsatisfactorily for rationalists, that agents involved in global solidarity projects such as CIGS are simply motivated by a desire to be better people-and that both motivations and interpretations of "better" stem from particular identities and communities, rather than from a transcendental understanding of rationality and obligation. Rejecting the opposition between morality and self-interest means that fostering global solidarity, or any other moral project, is not a matter of bypassing one's own desires and identity. Instead, global solidarity becomes a matter of sentimental education-a process which cannot pretend to exclude the self, and which aims for flexibility and sensitivity rather than impartiality or finality.

\section{Avery Kolers and Reason-Driven Solidarity}

Rationalist approaches to motivating global solidarity are skeptical of personal and particular motivations, which are seen as a source of potential bias, instead emphasizing the importance of impartial justice. Global solidarity is portrayed as the duty of all human beings to provide aid to those suffering injustices, and to address the structural problems that lead to these injustices (Kolers, 2005; Scholz, 2008). Spandler observes that, within the context of humanitarian aid, "rationalist perspectives usually take for granted that there exists a consensus on the fundamental purposes and principles of humanitarian action" $(2020,6)$. In discussions of the ethics of global solidarity this translates to an assumption that, at least under ideal circumstances, there would be general agreement that global solidarity represents a universal duty. The normative force of this duty to engage in global solidarity is assumed to be a compelling motivator in and of itself (Kolers, 2012, 1). Therefore, from a rationalist perspective, motivating global solidarity is a matter of overcoming individual bias and attaining clarity as to what actions our universal duties entail.

Avery Kolers offers a rationalist account of global solidarity that clearly distances itself from the sentimentalist acceptance of the role of individualistic self-creation in motivation. He writes, "... in solidarity one chooses sides for a reason that applies to people in general, not just to those who are in a certain relationship. I join in solidarity not because I think $I$ ought to, 
but because I think one ought to" (Kolers, 2016, 73). Kolers presents his version of global solidarity as "reason-driven political action on others' terms" (Kolers, 2016, 57). Reason-driven solidarity is presented as an alternative to both individualism, which motivates one to join in solidarity with those that share one's own interests and values, and loyalty solidarity, which motivates action based on existing commitments to a certain group. In short, Kolers argues that solidarity should be reasondriven in order to counteract the tendency to side with those one agrees with and those one has already formed relationships with.

When Kolers describes the political action motivated by global solidarity as "on others' terms", he has specific others in mind-those picked out by agent-neutral reasons. He claims that the only defensible form of solidarity is progressive solidarity, which is defined as reason-driven solidarity that commits one to join the side of the group that is "least-well off in a given social structure" $(2005,157)$. On this rationalist account, global solidarity is an obligation to use agent-neutral criteria that provide the motivational resources to join forces with distant out-groups in need of aid, thereby overcoming biases that stem from personal interests, moral intuitions, and existing loyalties. The value of global solidarity thereby lies in motivating support for the least well-off, regardless of whether or not one agrees with their goals or strategies.

On this structural view, conclusions made by outsiders motivated by global solidarity-whom Kolers refers to as "joiners"-that the tactics of the least well-off are unwise or even morally problematic, are based on moral intuitions that are products of the current status quo. In other words, efforts towards bottom-up empowerment cannot be productively evaluated using the moral intuitions of those at the top of existing social hierarchies. Here Kolers offers an interesting distinction between "acting in behalf of another and acting on their behalf. Whereas the former is the attempt to benefit them, the latter is the attempt to do what they would do in the situation" $(2016,22)$. Acting in behalf of others, attempting to improve the standing of suffering groups by outside standards, may address the outcomes of structural inequities but fails to meaningfully shift the status quo. Kolers argues that only acting on behalf of others qualifies as joining in global solidarity-as this involves acknowledging and deferring to the views of those disempowered by the existing social order.

Applied to the field of humanitarian aid, Kolers' rationalist approach to global solidarity presents some advantages. The structural focus and insistence on acting on others' terms serve as a reminder of the power dynamics between the groups involved in humanitarian crises. Connecting specifically to the localization of aid, if more ownership over crisis management is to be transferred to those with proximity to a crisis, this will inevitably require agents with less proximity to give up certain aspects of ownership. This will call for a willingness on the parts of outsiders to provide aid on others' terms - to recognize the strategies of those who think "wildly differently" as viable solutions to humanitarian problems. This interpretation of Kolers' rationalist approach to global solidarity connects to the localization of humanitarian aid insofar as it suggests that coordination efforts should grant a form of epistemic privilege to locals in recognition of the lack of collective hermeneutical resources that might make their tactics feel intuitive to outsiders. In other words, to the extent that those with proximity to a crisis and the "least well-off" can be assumed to overlap, reason-driven solidarity suggests that the viability of aid strategies should be increasingly evaluated on the grounds of proximity to the crisis and less on the grounds of compatibility with dominant global values and moral intuitions.

However, the idea of using reason-driven solidarity to avoid either widespread hegemony or individual bias encounters practical problems. The most obvious is that suggesting the use of agent-neutral criteria that determine who is "least welloff" in a given humanitarian crisis, assumes that there will be a general consensus as to who is "least well-off". Rather than moving past the particularities of Rortyan ethnocentrism with any finality, the proposed use of reason-driven solidarity simply raises the practical challenge of contextually defining proximity by one level of abstraction. In other words, returning to the example of Lesvos, a theoretical rationalization of motivation offers no objective criteria for determining how to defer to the multiple groups with legitimate claims to proximity to the crisis.

This can be connected to Spandler's comment about rationalist perspectives on humanitarian aid assuming the existence of consensus. Even in the unlikely case that there was a consensus among all aid agents that, for example, the Syrian refugees constituted the least well-off group, and there was a consensus among all Syrian refugees as to how to coordinate crisis relief-both the attempted empowerment of that group and any interpretation of their strategies would be colored by individual and group bias. An assumption of underlying consensus also increases the risk of treating diverse groups as homogenous. This is not to suggest that rationalist arguments about appropriate motivations of global solidarity cannot inspire praiseworthy attempts to avoid the potentially colonizing impacts of outside aid. It is instead an argument that rationalist approaches to global solidarity do not remove individual or group bias from the interpretations, applications, or motivations of global solidarity by including "reason-driven" or "on other's terms" in their theoretical formulations.

The contrast offered between Rorty and Kolers suggests that one set of tensions between sentimentalist and rationalist accounts rests upon the possibility and desirability of motivating global solidarity using neutral and impartial criteria. The differences between these accounts also parallel Rozakou's distinction between traditional, professionalized volunteerism and an emerging Greek alternative approach to volunteerism, which she describes as "a field of fluid and open sociality" (2016a, 95). Several studies of the Greek context describe this alternative volunteerism as a rejection of the political in favor of the social (Rozakou, 2016a, 82; Serntedakis, 2017, 84-85). This leads Serntedakis to conclude that egalitarian, anti-hierarchical attitudes and an aversion to top-down charity and philanthropy among volunteers in Greece, have led to an understanding of solidarity as "more about transforming social relations than trying to transform political systems" $(2017,95)$. 
It would therefore appear that CIGS and other informal volunteer groups in Lesvos are more aligned with a sentimental, affective, and relational view of the goals of solidarity. Remembering that Kolers defines global solidarity as political action on others' terms and highlights the need to attend to structural factors with impartiality, his rationalist view appears to be more in line with traditional volunteerism and established humanitarianism. With this tension in mind, we move now to Taylor's treatment of global solidarity, which offers additional conceptual resources for understanding when solidarity should aim to transform social relationships and when it should aim to support political resistance.

\section{Amanda Taylor and the Unidirectionality of Global Solidarity}

While rationalists such as Kolers conceptualize the global element in global solidarity as a matter of subordinating one's local loyalties to agent-neutral evaluations of structural inequities, sentimentalists such as Rorty see this global element of solidarity as a matter of expanding or adjusting one's attitudes about what constitutes group membership-so as to make one's loyalties as inclusive and flexible as possible. While Kolers hopes to cultivate an agent-neutral obligation towards those it might not come naturally to join forces with, Rorty hopes to motivate the empathic inclusion of as many groups as possible in an ethnocentric understanding of "one of us". Both theories, despite their numerous and significant differences, can be read as advocating concepts of global solidarity that focus on motivating what we will refer to here as "siding unnaturally".

A sense that one is on the same side as a suffering neighbor that one has developed a sense of local solidarity with, will come naturally for many. Actively siding with distant refugees, seems not to come as naturally, suggesting that global solidarity and siding unnaturally represent more demanding forms of motivation. Versions of global solidarity that focus on siding unnaturally present moral progress towards greater solidarity as an increased ability to move from, or past, local commitments to global commitments. Understanding the value of global solidarity through its ability to facilitate siding unnaturally, whether out of a sense of moral duty or due to a particular and personal commitment, is highly relevant in connecting global solidarity to the localization of humanitarian aid. The goal of siding unnaturally portrays the primary value of global solidarity as a means of motivating the involvement of those who are not in close proximity to humanitarian emergencies. While global attention and contributions are key in addressing humanitarian crises, there is a potential conflict between efforts to mobilize global involvement and efforts to localize ownership of crisis management.

Conceptions of global solidarity as siding unnaturally can be problematized by the work of Amanda Taylor, who distinguishes between robust solidarity and expressional solidarity $(2015,129)$. As with the local/global distinction offered in this paper, one key feature differentiating Taylor's two types of solidarity is group membership. Robust solidarity exists between members of an established group acting together in pursuit of joint interests that they cannot realize individually. The robust form of solidarity requires reciprocal empathy, mutual recognition among group members, and a shared sense of trust. Taylor describes expressional solidarity as support that comes from those outside the robust solidary group. When solidarity is expressional, elements such as identification, trust, and empathy are unidirectional and sometimes primarily "motivated to ensure recent events get attention in the West" (Taylor, 2015, 132).

Although demonstrations of expressional solidarity might potentially set one on a path towards membership in a group that shares robust solidarity, Taylor argues convincingly that the robust solidarity between insiders is a matter of acting on mutual obligations and positive duties, while the expressional solidarity engaged in by outsiders is a matter of acting on motivation. In other words, when a group is affected by a crisis, the robust solidarity that exists within the affected group generates obligations or responsibilities to protect the group's interests and well-being. Non-members may experience expressional solidarity with the out-group in crisis, and this may motivate these non-members to work to protect that out-group's interests and well-being. However, the two forms of solidarity do not have the same normative composition $(2015,28)$.

While interests may be shared between those displaying expressional solidarity and those engaged in robust solidarity, these are characterized as parallel interests rather than joint interests. Taylor argues that solidarity is unique in that it "involves adopting the group's interest as one's own and linking the achievement of such interests with one's own wellbeing" $(2015,133)$. Importantly, this process of making a group's interests integral to one's sense of self is compatible with both expressional and robust solidarity-with having either parallel or joint interests. The difference between the two hinges on the unidirectional or multi-directional nature of the investment. Through global solidarity one can come to identify the struggle of a distant out-group as one's own. When this identification with the group in crisis is unidirectional, meaning one comes to identify an out-group's interests as deeply connected to one's own well-being, solidarity is expressional. Only when there is multidirectional identification, meaning one is also identified by the group as included in the obligations generated by group-membership, does solidarity qualify as robust ${ }^{2}$.

There is an important sense in which both the rationalist and sentimentalist versions of global solidarity as siding unnaturally espoused by Kolers and Rorty suggest that global commitments to distant out-groups embody the more demanding version of solidarity. From the perspective of generating motivation, they may be right. However, we read Taylor's distinction as suggesting that the obligations incurred

\footnotetext{
${ }^{2}$ Our use of Taylor's distinction between robust solidarity and expressional solidarity emphasizes her treatment of identification and joint interests in order to highlight parallels to our own distinction between local solidarity and global solidarity. Taylor's original article places a greater emphasis on mutual trust and a disposition to empathy than is expressed here.
} 
upon existing members of a solidary in-group are in fact more demanding and carry a stronger normative force than the efforts of out-groups to express, what we refer to as, global solidarity. This claim is not intended to minimize the demanding nature of engaging in global solidarity. It is instead intended as a warning against assumptions that the challenging task of motivating involvement with distant outgroups and the intensity of encounters that make the crises of others one's own, warrant a sense of what we might call reciprocal or robust ownership of the crisis on par with that of the groups most directly affected.

The reciprocity and multi-directional identification that Taylor describes in robust solidarity are arguably not present, or at least not necessary, in international humanitarian aid (Gould, 2007, 157). It is incumbent upon those motivated by global solidarity to consider that, as "expressional solidarity is largely unidirectional, then there is a danger that when I express solidarity with you, I project my own vision of you into the solidaristic relationship, and thus my solidarity is not with you as you, but with you as my idea of you" (Woods, 2019, 151). This potential for projection can be combined with Taylor's distinction between joint interests and parallel interests to problematize conceptions of global solidarity that emphasize the motivation of siding unnaturally. Kolers' arguments for “joining” in global solidarity and Rorty's call to think of the members of suffering out-groups as included in our sense of "one of us", carry with them a serious colonizing potential if not accompanied by a thorough consideration of whether or not the groups with which global solidarity is being expressed are interested in outsiders "joining" or becoming "one of them" in a robust sense.

Taylor's distinction can be equally useful when applied to international efforts to take the strategies of those with various forms of proximity to a humanitarian crisis seriously. While global solidarity is highly demanding, it is often unidirectional and may represent parallel interests rather than multidirectional or robust obligations towards joint interests. Specifically, in the context of Lesvos, Rozakou has observed that the dominant understanding of solidarity among volunteers "seeks to overcome the limitations and the perils deriving from one-way offers" $(2016 \mathrm{~b}, 189)$. We argue that overzealous efforts on the parts of international actors to turn their global solidarity into robust solidarity may in fact have a disempowering effect on those groups most affected by crises. This underlines the importance of consciously keeping the global solidarity of international aid efforts at the level of expressional solidarity. Distinguishing between the local and global forms of solidarity, and between robust and expressional commitments, can offer insights into the potential coordination of groups with different senses of proximity to humanitarian crises. As suggested earlier, this represents a major challenge in contextualizing and practically implementing the localization of humanitarian aid. Later discussion of this conceptualization will draw on illustrative examples from our own fieldwork in Lesvos, to which we now turn.

\section{METHODOLOGICAL APPROACH}

This paper is based on data collected on and in Lesvos between 2015 and 2019. Our empirical data consist of qualitative interviews, observations, and participant observations and are thus grounded in ethnography. Prior to our first round of fieldwork in 2016, we followed the unfolding crisis in Lesvos through mainstream news and social media. Here we focused on how CIGS emerged as a response to the influx of refugees to the island. It was our previous research on CIGS in a development context (Haaland and Wallevik, 2017) that spurred an interest in the initiatives that popped up in Lesvos. These initiatives-that quickly organized to respond to various aspects of the crisis in Lesvos-were followed online with a particular emphasis on their activities, especially their efforts to help during the peak of the crisis. The material collected online provided us with an initial overview of the types of engagement that emerged in Lesvos during 2015. At the same time, an initial mapping of CIGS in Norway showed that out of 350 initiatives that were portrayed in local newspaper articles from 2000 to 2016, 83 were refugee related, with ties to Greece and Lesvos. Since 2015, the number of Norwegian aid initiatives that targets refugees, including those in Lesvos, has continued to grow (Fylkesnes et al. forthcoming). This data formed a backdrop for our further data collection in the field, as some of the initiatives were followed up and further interviewed during our various field stays.

Our on-site fieldwork in Lesvos started in 2016. During five shorter field stays over the years 2016-2019 we conducted interviews with founders and members of initiatives that worked with the refugee crisis. To capture the rapid changes and the ways initiatives responded to change over time, several informants have been interviewed multiple times. We have also engaged in numerous discussions with representatives of the local government who had established a local response team. Additionally, we have interviewed representatives from both UNHCR and larger NGOs to contextualize the role of CIGS within the broader network of crisis response in Lesvos. Both informal and formal interviews were also conducted with residents in Lesvos, especially those involved in tourism, an industry which has been impacted by the refugee situation. This provided insight into everyday practices, local discourses, and perceptions of the situation amongst local people. As such, it contributed to further contextualizing the understanding and handling of crisis. We also visited the three refugee camps on the Island: Lesvos Solidarity, Kara Tepe, and Moria. The latter refers to the camp located near the village of Moria prior to the fire in 2020. These visits provided opportunities to observe the roles CIGS assume within the camps, and to speak with camp managers, volunteers, and refugees.

During our first stay we travelled around the island and observed responses to the large numbers of refugees arriving at the shores of Northern Lesvos, walking across the island to get to Mytilini, and attempting further travel to mainland Greece. Moving across the island as part of our field work has enabled continuous informal conversations with people who had been involved in voluntary work. Our travels facilitated participant observations which were recorded in field notebooks. Several 
residents became gatekeepers who further facilitated access to the local communities we encountered. We quickly discovered that almost every one of our Greek informants had been involved in early efforts to prepare food, provide transport, or contribute in some way to CIGS. However, both the positive sentiments towards refugees and the local optimism about the viability of humanitarian aid deteriorated amongst many of our informants as the crisis continued. Our numerous field trips allowed us to observe the evolutions of various narratives of crisis, which reflected developments in the local, political, and economic context.

In May 2017, we participated in the "Mini Lesvos dialogues"-meetings set up to enable a variety of actors involved in the crisis to discuss their experiences and strategies. The meetings allowed for further recruitment of informants for our research. We returned for a second dialogue session in 2019. These two dialogue meetings enabled us to explore both cooperation and tensions between the actors involved, all of whom experienced and engaged with the crisis from different perspectives. Several shorter field visits to the island enabled us to, over time, follow CIGS and other actors, observing both changes and continuities in their work. In total, we have interviewed 15 CIGS owners who have been working in Lesvos both prior to and during the crisis. In addition, we conducted interviews with members of local government, NGO representatives, and employees from each of the three refugee camps mentioned above. Snowball sampling guided our selection of interviewees. The interview data has been transcribed and anonymized. All names used in the article are thus fictive names.

During the collection and analysis of data, the type of work that various CIGS engaged in and the ways they coordinated with, resisted, or otherwise related to the other actors involved was emphasized. This approach is inspired by Institutional Ethnography (Smith, 2005) and explores how the ruling relations, efforts, and discourses of other actors govern CIGS in their activities. Our research on CIGS therefore included investigating the local communities they engage, whether Greek citizens or refugee populations, as well as other actors such as NGOs, the local and central governments, and UNHCR. As such, we have been concerned with how CIGS and other actors present and perceive themselves vis-à-vis other actors, as well as how they perceive and talk about other aid actors and the refugee situation on the island and beyond. Consequently, attention is paid to the overarching context and the ruling relations, such as local and national policies and humanitarian discourse.

As CIGS are not universally considered to be legitimate actors within development and humanitarian assistance, much of what they do remains invisible to the other actors. A standpoint within CIGS and their everyday work illuminates how and to what extent they are guided by the social relations they take part in, both locally and trans-locally, i.e., what relations and ruling relations are guiding their work (Smith, 2005). Emphasis on their activities enables us to understand their work as socially coordinated in response to crisis. Insights into CIGS' perceptions of themselves and others contributes to research on CIGS and other actors involved in networked crisis management.

\section{LOCAL COORDINATION AND GLOBAL ATTENTION}

It is important to differentiate between the CIGS operating in a crisis context, such as Lesvos, and those operating in a development context. Development-oriented CIGS generally work informally and "under the radar" of local authorities, often enjoying a degree of freedom from local bureaucracies, policies, and guidelines (Haaland and Wallevik, 2017). Rather than acting as part of a coordinated development aid response, these CIGS focus on the individual needs of particular communities. In contrast, CIGS that respond to acute humanitarian crises are often monitored and integrated into overarching crisis management strategies. In Lesvos, for example, international CIGS are registered as soon as they arrive (Haaland and Wallevik, 2019). This registration has been necessary to monitor the multitude of actors that have been involved over the course of the crisis.

The initial response fell to the locals who were, fortunately, accustomed to the arrival of refugees. They were, however, unequipped to handle the thousands of refugees that arrived unexpectedly in 2015, the majority of whom were fleeing the conflict in Syria. As part of the initial response, members of the tourism industry made their premises available as refugee shelters while other islanders arranged transport and gathered food and clothes. Locals also helped boats ashore, provided blankets, and constructed temporary shelters (Guribye and Mydland, 2018). Numerous international volunteers and CIGS, responding to the crisis depicted in both mainstream and social media, worked alongside the locals. Many of these CIGS established working relationships with local organizations and the local government, functioning as organized parts of a local response that laid the foundation for the coordinated crisis management that developed when UNHCR and larger international NGOs arrived in 2016.

Since the arrival of the larger international actors, a coordinated effort, led by UNHCR and the local government, has incorporated several of the smaller CIGS. The CIGS operating outside this coordinated effort run their activities parallel to the crisis management team, often advocating alternative strategies (Haaland and Wallevik, 2019). Adding to the complexity of the situation, the refugee camps in Lesvos are not run by a single centralized body. Moria, the largest refugee camp on the island, is run by the central Greek authorities, while the smaller camp of Kara Tepe is run by local authorities. While the local government points to Kara Tepe as a showcase of Greek hospitality, they argue strongly against the establishment of more permanent refugee accommodations in Lesvos.

Rather than accommodating refugees on the island, the local government argues that the demands of the crisis should be increasingly shared by mainland Greece and the EU. This argument represents the islanders' eagerness to restore normality and tourism, which is a major source of local income. While some tourist businesses, particularly those located near the Island capital, are able to generate revenue from NGO workers, CIGS, and volunteers, others have seen their incomes radically reduced. Many locals explicitly blame the refugees for the lack of tourism and increasingly refer to 
refugees as migrants, an expression of their frustration with the longevity of the situation.

Many of the large NGOs eventually left, leaving a growing role for the CIGS that have remained on the island. These initiatives are taking care of everyday needs both inside and outside formal and informal camps, while also making efforts to direct global attention to the continued humanitarian crisis. A solution to the crisis seems distant and refugees and islanders alike are tired. Tensions regarding how to live with, engage in, and possibly solve the situation are omnipresent. The tensions observed during our fieldwork can be categorized into two sets of contested interests, which we describe as "coordination of local crisis management" and "global attention".

Turning first to the coordination of local crisis management, one continued attempt can be seen in the weekly coordination meetings run by UNHCR, in dialogue with the local government. At these meetings, actors involved in various forms of crisis response offer updates on their activities and discuss future strategies. Over the years we have seen parallel efforts towards coordination develop amongst CIGS, but we have also heard reports of competition between aid actors. Many CIGS are critical towards the local government and the UNHCR, and therefore purposefully work outside of the larger coordination efforts. Some experience the coordination mechanisms imposed by more established humanitarian aid agents as inflexible and lacking sensitivity to the local community:

"I mean, the UNHCR, they came at the beginning. It was like 'We know everything. We speak English, only English, in all coordination meetings.' This is not acceptable. And they are wondering why, why the authorities are not here, why hospital is not here. You are in Greece! Speak the language! Or make the translation-I know it takes time. But this is also a symbol. I mean, you give the signal that you don't respect" (Claire, woman 50 years, 2017).

Included in the sharp criticism of the perceived colonizing presence of UNHCR, were frustrations with the way UNHCR took control over projects that were being carried out by local organizations and CIGS in the early months of the crisis. This structural transition created lasting tensions between the larger organizations, on the one side, and the smaller initiatives and local population on the other. The disappointment with being unceremoniously pushed aside upon the arrival of established organizations was bolstered by a skepticism towards the resource flows of these larger actors:

"I'm not sure about the UNHCR as an organization. But they are a big money-making machine. They spend a lot on advertising. That grieves me" (Patty, woman 50 years, 2017)

The concern with the use of funds voiced by CIGS members was also widespread among citizens of Lesvos. However, this local skepticism was also directed towards
NGOs, CIGS, and international volunteers who were perceived as driven by self-interest or as more invested in the refugees than in finding permanent solutions that would benefit local communities. The fact that both formal and informal international aid agents will eventually move on can lead to a sense of solidarity that exists in transition (Oikonomakis, 2018, 68). The temporary presence of outsiders is all the more reason to emphasize local ownership of crisis management and to keep global solidarity at an expressional level.

Local interview participants suggested that the government should manage the refugee situation despite the necessity of foreign contributions. They argue that NGOs and other international actors serve an inappropriate function, as substitutes for the government:

"That should not happen. NGOs should be something
complementary and not a substitute. We always see
NGOs drawing money from the natives, from the
government, from the EU, and doing its jobs. But we
believe it is a government's job, it is the citizens' job, to
be there ... This way, we believe that the very fact of
democracy is being undermined. Right now, the money
from the EU was given to NGOs. The ministry asked
Save the Children for funds, to use for education. That is
a degradation. Governments asking NGOs. Who
controls the NGOs? Of course, who controls the
government? And who trusts the government?"
(Ilhias, man 40 years, 2016).

In this example, frustrations point to the complicated and overlapping roles played by a wide range of organizations in the current attempts to coordinate crisis management. Some of these frustrations are directed at the established crisis management team, which is comprised of local government, UNHCR, NGOs, and selected CIGS. However, despite the call for a larger role for government, there is also an unmistakable suggestion that the government is not trustworthy. This seems to suggest that, ideally, the government should be working more with local citizens and less with the international NGO establishment. From this perspective, the localization of humanitarian aid might offer coordination solutions and restore local faith in the government.

However, from the perspective of the local government, the main impediments to efficient coordination are the uncooperative CIGS and international volunteers that resist the coordination efforts of the established crisis management team:

"But these are doing more harm than good. Because they are not coordinated. It's no use to have people distributing food when you need people welcoming boats, for example” (Marcus, man 30 years, 2016)

"People lacking experience come in and set up a tent and do their thing; this is not contributing to the overall management of the crisis." (ibid) 
Specifically, parallel projects that aim to achieve the same ends as local government projects, but refuse to join in coordinated efforts, are seen as individualistic troublemakers rather than competent contributors:

"Why not helping the overall situation? Why? Because they want to do something of their own. Because they do not believe in the coordination mechanism. Because they do not trust UNHCR." (ibid)

These misgivings are echoed by UNHCR and other larger organizations, who express concerns about a lack of professionalism in the CIGS involved in crisis relief. Larger, specialized organizations bring professionals to cater to specific needs that they have a degree of familiarity with. They question the ability of well-intentioned amateurs to, for example, provide care for traumatized, refugee children:

"You want to help children, but what do you know about child development? Cultural sensitivity? Or are you just a person who thinks 'I want to help'?" (Themis, Man 35 years, 2016)

Within the UNHCR's skepticism towards CIGS' lack of experience is an implicit critique of the instability generated by cooperation between local government and CIGS. In the management of Kara Tepe, for instance, the local government relies heavily on services from smaller, recently founded initiatives. When CIGS uncritically accept assignments, failing to reflect on the sustainability of the privately generated funds they depend on to continue their work, this can introduce instability into the core operations of the camps.

Interestingly, criticisms regarding the abilities of certain types of aid agents to relieve the crisis in Lesvos appear to cut both ways. On the one hand, UNHCR criticizes CIGS for lacking the professionalism and experience to deal with a humanitarian crisis. At least some CIGS are described as doing more harm than good due to their resistance towards an overarching "coordination mechanism". On the other hand, the CIGS criticize the UNHCR for relying on professionalism and outside experience too such an extent that they become dispassionate and insufficiently attuned to cooperative relations that were developed before the arrival of the larger organizations. We interpret the resistance of CIGS as a critique of existing coordination mechanisms, rather than a resistance of coordination as such. The resistance stems from both concerns that funds are not being spent appropriately and a perceived lack of respect for locals and small-scale aid operations. These tensions demonstrate a clear absence of a shared understanding of joint interests among the actors attempting to provide aid to refugees and the citizens of Lesvos.

Turning to the second contested interest, "global attention," we have observed that many locals feel at cross-purposes with humanitarian aid agents. The residents of Lesvos struggle with the economic impacts of the refugee situation while simultaneously seeing large amounts of resources being mobilized in attempts to provide aid. Despite global attention and contributions, the challenges of the locals remain. Over the course of our fieldwork, we witnessed a growing perception of outsiders as motivated by financial self-interest or a desire to feel good about themselves, rather than a desire to provide meaningful aid:

"...they only care about what they feel. They want to feel pleased that they helped someone." (Alexandros, man 40 years, 2016)

With active members of the local community going so far as to say, for example:

"Refugees are not the problem, but volunteers are." (Ilhas, man, 40 years, 2017)

Long term volunteers are familiar with such attitudes and find them burdensome. As one volunteer expressed:

"In my town ... (i.e. where the interview participant volunteers) I was told to go home ... That I was making too much money. That's why I have come" (Margareth, woman, 25 yrs, 2017).

If international support is perceived as corrupt or inefficient, this naturally affects the desirability of directing further global attention towards the situation in Lesvos. An additional tension can be seen between outsiders who are interested in portraying a crisis to generate awareness or donations, and locals who are interested in portraying a sense of normality. CIGS, volunteers, and representatives of international NGOs have scaled up their presentations of the Lesvos crisis, in the absence of mainstream media attention. These presentations are interpreted by some locals as maintaining the crisis and as preventing a revival of the tourist industry, as seen in the following comments from a local businessperson:

"At the moment there is a big lack of marketing that Lesvos is not suffering, in a way, with any bad conditions of refugee crisis. So, people (tourists) do not know to arrive back." (Stavros, man, 50 years, 2016)

Later adding:

"I need to be persuaded that the NGOs are going to solve my problem and not maintain it. The NGOs they were maintaining the problem ... competing themselves, who is going to save more people so they can get approved more grants. The Facebook pages and everything were full of photos: 'We saved these guys. We saved these guys. Please help us. Send us money'. Whatever. It happened. It happened on Facebook and everybody can see it." (ibid)

These comments illustrate a clear sense in which generating global attention on outsiders' terms may be preventing groups 
with proximity to the crisis from reestablishing themselves. Media representation of the refugee situation offers a striking example of Taylor's point that unidirectional, expressional attempts at global solidarity can prioritize the attention of the West over the need to rebuild local communities.

Competing interests concerning the international representation of Lesvos have complicated the coordinating role of the local government, which is positioned between an upward accountability to the national government and the EU and a downward accountability to local citizens (Williams, 2010). CIGS have also experienced the impacts of these tensions between those arguing for a revival of the tourism sector and those attending to the needs of refugees. While some CIGS have simply given up due to negative feedback, others have distanced themselves from the established aid machinery and carefully communicated to the locals that they are not NGOs. One organization hung a sign over their office announcing this, which speaks to the intensity of local frustration with aspects of the international response. This can be interpreted as part of the resistance towards the professionalization of volunteerism and aid that Rozakou describes as emerging in Greece (2016a, 95), and as a need to distinguish solidarity from charity and established humanitarianism.

Alongside the closure of some initiatives, new initiatives have emerged. Some have been started by refugees working within the camps, while others have been started by former refugees hoping to meet the needs of both current refugees and islanders living with the impacts of the crisis. Some of these refugee-run initiatives receive international funding and attention, which may offer a compromise between representations of crisis and representations of cooperation and progress towards normalcy. However, reestablishing positive perceptions of refugees among the locals is no easy task. Conservative political groups have thrived on anti-refugee attitudes in the local population. The prospect of refugees being offered local jobs, being enrolled in local schools, or finding permanent housing is often met with resistance.

In summary, we observed increasing suspicion from locals towards refugees and outside aid, as well as tensions between aid agents regarding each other's respective competencies in navigating the situation in Lesvos. These issues center around coordination, motivation, the use of funds, and representations of the situation in Lesvos. Having looked at empirical examples of competing interests that arise in both coordinating local crisis management and representing the need for global involvement, we can return to the attempt to balance the appeal of increased localization of aid and the appeal of increased global solidarity.

\section{A SUPPORTING ROLE: PROXIMITY WITHOUT OWNERSHIP}

The increase in global solidarity that CIGS appear to be calling for by resisting established coordination mechanisms has two components, which mirror the tensions mentioned in the previous section. First, there is a call for more global attention and action, which we have interpreted as potentially problematic if not connected to the competing interests of those with proximity to the crisis. Second, the act of engaging a humanitarian crisis at a more horizontal, empathic, and relational level-rather than joining with larger, more established aid agencies-suggests that the perceived gaps in the international response include a failure to offer personal encounters that meet refugees and locals as individuals, rather than cogs in a machine.

Turning first to the idea of an increase in global solidarity as a call for more international responsibility, representation must play a key role. We have presented the tension in Lesvos between an interest in representing a crisis to motivate or finance outside involvement and an interest in representing normality to revive the local economy. Taylor's claim that some cases of expressional solidarity focus on getting the attention of the West, could be interpreted as suggesting that the dissemination of narratives of suffering to motivate global solidarity fails to account for the conflicting interests of affected, local communities. Kolers would describe these attempts to motivate global attention as acting in behalf of the locals, and thus as not qualifying as global solidarity at all.

In one sense, this tension could be addressed through a localization of aid, in which local communities were given more ownership over the process of globally representing humanitarian crises and crisis management. This acknowledges the unavoidable global element of humanitarian aid, namely the recruitment of outside resources, and localizes the ownership of this process in a way that recognizes the interests of those affected by the crisis. This would amount to a localization of the call for global solidarity. Of course, at the level of practice, there are conflicting interests between and within groups with legitimate claims of proximity to the crisis, and there would be no way to control the totality of representations-especially on social media. Despite these challenges, any degree of local ownership in the process of directing global attention to the situation in Lesvos would contribute to a sense of local empowerment and demonstrate recognition of the local impacts of foreign aid. While the specifics of such a project are beyond the scope of this paper, this suggestion offers an example of productive interplay between efforts towards increased global solidarity and increased localization of aid.

Turning to CIGS' second critique of established aid, the lack of empathic relationality, these frustrations are aligned with Rorty's sentimentalist conceptualization of global solidarity to the extent that the CIGS are criticizing a lack of sensitivity, flexibility, and inclusion. CIGS' resistance towards aid strategies that do not prioritize an empathic form of global solidarity are supported by Arampatzi's argument that solidarity distinguishes itself from charity through its opposition towards "disembodied caring from a distance" (2017, 2,161). Distance seems to represent the primary obstacle to the motivation of global solidarity. Certainly, the difficulty of motivating personal and empathic action that addresses a crisis to which one has no obvious sense of proximity, should not be underestimated.

Members of CIGS were open about the traumas of encountering dead bodies, observing inhumane conditions, and hearing the harrowing stories of refugees. For example, one volunteer recounted the intensity of another woman's experience: 
"She was doing an English lesson with a young man, that starts telling her his journey, everything. And she was in bits for the rest of the day. She couldn't handle it. But she cared and she heard him. She just needed help to get through the day afterwards. And there's a bit of me say 'Oh oh oh, shouldn't have let that happen'- professionally, but then there is also the bit of me that says, 'She's people helping people"'. (Patty, woman 50 years, 2018)

The personal connection between the volunteer and the young man offers a clear example of the ability of solidarity to motivate one to go beyond "disembodied caring from a distance". Patty's reflections also demonstrate the potential for tension between professionalization and horizontal empathy at the level of the individual. This narrative demonstrates the potential that personal interactions have for offering important forms of care, but also the intensity of such experiences.

As argued earlier, the transformative nature of engaging distant others in global solidarity can make a formerly distant crisis one's own in an important sense. Recall that Taylor argued that all forms of solidarity involve making the interests of a group central to one's own sense of well-being. However, in the interests of promoting the localization of humanitarian aid and in the interests of avoiding the reproduction of colonialist hierarchies, it must be acknowledged that this process of "making the crisis one's own" is often unidirectional. In this context, this means that the benefits of CIGS members' transformative, solidary acts, that cause them to become personally invested in a crisis, should not be measured in terms of the eventual inclusion of these individuals in robust solidarities. Regardless of the intensity of one's commitment, the global solidarity of those engaged in foreign aid should generally be conceptualized as expressional.

Categorizing solidarity as "expressional" should not invoke images of social media activism or simply paying lip service to a cause. We argue that expressional global solidarity is by no means detached caring from a distance, but it does imply not taking unnecessary ownership of the aid process. Arguing that global solidarity in humanitarian crises should remain expressional prioritizes motivating unidirectional and personal identifications with a cause and warns against either aspiring towards or assuming multidirectional recognition of oneself as a member of the robust solidary group. Through awareness of their structural position within a crisis situation, outsiders can express global solidarity without expressing a sense of ownership. A version of this approach is present in the following reflections from a CIGS member on her work with refugees in Lesvos:

"It's not been a caring profession; it's been a supporting profession. It sounds like ... I do care. I care passionately, but I'm not a caretaker. I'm not there to take over, to do everything. I'm there to send people on their way, and I think that's what people need here. To send people on their way in the best possible way." (Patty, woman 50 years, 2018)

The idea of caring without assuming the role of a caretaker, neatly captures the idea of making a crisis one's own without identifying with something larger than a supporting role-working in proximity to a crisis without assuming that one's proximity must warrant robust membership of some kind. Especially if global solidarity and the localization of aid are to be compatible, expressional global solidarity appears to be what is called for in international responses to humanitarian crises. Returning to Spandler's description of the localization of humanitarian aid as demanding "more ownership for state and non-state actors in close proximity to the emergencies," we argue that the type of proximity that warrants this type of ownership is membership in one of the robust solidary groups directly affected by the crisis.

There are certainly other legitimate interpretations of proximity. The speed with which many international CIGS organized and became functioning parts of the local response in the early months of the crisis, offers one example. Their frustrations with being dismissed by larger organizations were likely connected to the degree of proximity to the crisis that these CIGS had worked to develop. However, despite having built relationships with locals during the initial crisis response, we argue that this proximity is still unidirectional. By this we mean that the proximity that was developed, the distance that was navigated in global solidarity, was a matter of outsiders motivated to work towards the interests of groups they were not members of.

We argue that the localization of humanitarian aid represents, in part, spreading a reflexive awareness among outside actors that the goal of global solidarity should be to motivate parallel efforts that support the joint interests of those most affected, and wherever possible, do so on their terms. Expressional global solidarity, when localized, does not imply any decrease in commitment. Just as an important part of offering relational support to a friend in crisis would be to avoid making the exchange about oneself, the unidirectional nature of support offered to distant others in expressional global solidarity does not entail a lack of wholehearted empathy. We argue that if empathic responses to humanitarian crises are to accommodate both global solidarity and local empowerment, the primary challenge for outsiders lies in balancing the personal and transformative experience of engaging in global solidarity with a commitment to a supportive role that prioritizes the joint interests of those with greater and more long-lasting proximity to these crises.

\section{DATA AVAILABILITY STATEMENT}

The raw data supporting the conclusions of this article are not publicly available due to restrictions concerning information that could compromise the privacy of research participants.

\section{ETHICS STATEMENT}

The fieldwork conducted is in line with NSD guidelines. All research participants have provided their consent for participation in the research project.

\section{AUTHOR CONTRIBUTIONS}

LMS contributed to the overall coordination of the paper, the analysis of existing theories of solidarity and the summary theoretical discussion. $\mathrm{HH}$ and $\mathrm{HW}$ conducted the fieldwork 
upon which this paper was based, contributed large portions of the section on methods, and contributed to the discussion and

\section{REFERENCES}

Arampatzi, A. (2017). The Spatiality of Counter-austerity Politics in Athens, Greece: Emergent 'urban Solidarity Spaces'. Urban Stud. 54 (9), 2155-2171. doi:10.1177/0042098016629311

Baier, A. (1991). A Progress of Sentiments: Reflections on Hume's Treatise. Cambridge MA, NY: Harvard University Press.

Bartky, S. L. (1998). Pitfalls and Politics of" World-Traveling. Philosophical Stud. Int. J. Philos. Analytic Tradition 89 (2/3), 387-393. doi:10.1023/a: 1004218021185

Bauder, H., and Juffs, L. (2020). 'Solidarity' in the Migration and Refugee Literature: Analysis of a Concept. J. Ethnic Migration Stud. 46 (1), 46-65. doi:10.1080/1369183X.2019.1627862

Cantat, C. (2018). The Politics of Refugee Solidarity in Greece: Bordered Identities and Political Mobilization. Budapest: CPS/MigSol Working Paper 1.

Chouliaraki, L. (2013). The Ironic Spectator: Solidarity in the Age of PostHumanitarianism. Malden, MA: John Wiley \& Sons.

Daskalaki, M., and Kokkinidis, G. (2017). Organizing Solidarity Initiatives: A Socio-Spatial Conceptualization of Resistance. Organ. Stud. 38 (9), 1303-1325. doi:10.1177/0170840617709304

Fechter, A-M., and Schwittay, Anke. (2019). Citizen Aid: Grassroots Interventions in Development and Humanitarianism. Taylor \& Francis.

Gould, C. C. (2007). Transnational Solidarities. J. Soc. Philos. 38 (1), 148-164. doi:10.1111/j.1467-9833.2007.00371.x

Gould, C. C. (2020). "Motivating Solidarity with Distant Others", in The Oxford Handbook of Global Justice. Editor T. Brooks, 121-138. doi:10. 1093/oxfordhb/9780198714354.013.6

Guribye, E., and Mydland, T. S. (2018). Escape to the Island: International Volunteer Engagement on Lesvos during the Refugee Crisis. J. Civil Soc. 14 (4), 346-363. doi:10.1080/17448689.2018.1518774

Haaland, H., and Wallevik, H. (2019). Beyond Crisis Management? the Role of Citizen Initiatives for Global Solidarity in Humanitarian Aid: The Case of Lesvos. Third World Q. 40 (10), 1869-1883. doi:10.1080/01436597. 2019.1656060

Haaland, H., and Wallevik, H. (2017). Citizens as Actors in the Development Field: The Case of an Accidental Aid-Agent's Activities in Aid-Land. Forum Stud. 44, 203-222. doi:10.1080/08039410.2017. 1305444

Kolers, A. (2005). Justice and the Politics of Deference*. J. Polit. Philos. 13 (2), 153-173. doi:10.1111/j.1467-9760.2005.00218.x

Kolers, A. H. (2012). Dynamics of Solidarity. J. Polit. Philos. 20 (4), 365-383. doi:10. $1111 /$ j.1467-9760.2010.00391.x

Kolers, A. H. (2016). A Moral Theory of Solidarity. New York City: Oxford University Press.

Lenard, P. T., Straehle, C., and Lea, Y. (2010). Global Solidarity. Contemp. Polit. Theor. 9 (1), 99-130. doi:10.1057/cpt.2009.46

Lenard, P. T. (2010). Motivating Cosmopolitanism? A Skeptical View. J. Moral Philos. 7 (3), 346-371. doi:10.1163/174552410x511437

Lugones, M. (1987). Playfulness, "World"-Travelling, and Loving Perception. Hypatia 2 (2), 3-19. doi:10.1111/j.1527-2001.1987.tb01062.x

Malkki, L. H. (2015). The Need to Help: The Domestic Arts of International Humanitarianism. Duke University Press. doi:10.2307/ j.ctv125jptn

Oikonomakis, L. (2018). "Solidarity in Transition: The Case of Greece," in Solidarity Mobilizations in the 'Refugee Crisis'. Editor D. D. Porta (Palgrave Macmillan), 65-98. doi:10.1007/978-3-319-71752-4_3

Rakopoulos, T. (2014). Resonance of Solidarity: Meanings of a Local Concept in Anti-austerity Greece. J. Mod. Greek Stud. 32 (2), 313-337. doi:10.1353/mgs. 2014.0040 analysis of the fieldwork and interview data, in light of the theoretical framework.

Rorty, R. (1989). Contingency, Irony, and Solidarity. Cambridge: Cambridge University Press.

Rorty, R. (1991). Objectivity, Relativism, and Truth: Philosophical Papers., Vol. 1. Cambridge: Cambridge University Press.

Rorty, R. (1998). Truth and Progress: Philosophical Papers, Vol. 3. Cambridge: Cambridge University Press.

Rozakou, K. (2016a). Crafting the Volunteer: Voluntary Associations and the Reformation of Sociality. J. Mod. Greek Stud. 34 (1), 79-102. doi:10.1353/mgs. 2016.0014

Rozakou, K. (2016b). Socialities of Solidarity: Revisiting the Gift Taboo in Times of Crises. Soc. Anthropol. 24 (2), 185-199. doi:10.1111/1469-8676. 12305

Rozakou, K. (2017). Solidarity\# Humanitarianism: The Blurred Boundaries of Humanitarianism in Greece. Etnofoor 29 (2), 99-104.

Sandelind, C., and Ulaş, L. (2020). Solidarity with Refugees: An Institutional Approach. J. Soc. Philos. 51 (4), 564-582. doi:10.1111/ josp. 12333

Scholz, S. J. (2008). Political Solidarity. University Park, PA: Penn State Press.

Schulpen, L., and Huyse, H. (2017). Editorial: Citizen Initiatives for Global Solidarity. The New Face of European Solidarity. Forum Stud. 44, 163-169. doi:10.1080/08039410.2017. 1306956

Serntedakis, G. (2017). 'Solidarity'for Strangers: A Case Study of 'Solidarity'Initiatives in Lesvos. Etnofoor 29 (2), 83-98.

Smith, D. E. (2005). Institutional Ethnography: A Sociology for People. Washington, DC: Rowman Altamira.

Spandler, K. (2020). Saving People or Saving Face? Four Narratives of Regional Humanitarian Order in Southeast Asia. Pac. Rev., 1-30. doi:10.1080/09512748. 2020.1833079

Straehle, C. (2020). Associative Solidarity, Relational Goods, and Autonomy for Refugees: What Does it Mean to Stand in Solidarity with Refugees?. J. Soc. Philos. 51 (4), 526-542. doi:10.1111/josp.12339

Taylor, A. E. (2015). Solidarity: Obligations and Expressions. J. Polit. Philos. 23 (2), 128-145. doi:10.1111/jopp.12035

Thayer-Bacon, B. (2010). A Pragmatist and Feminist Relational (e) Pistemology. Eur. J. Pragmatism Am. Philos. II (1), 1-22. doi:10.4000/ejpap.948

Theodossopoulos, D. (2016). Philanthropy or Solidarity? Ethical Dilemmas about Humanitarianism in Crisis-afflicted Greece. Soc. Anthropol. 24 (2), 167-184. doi:10.1111/1469-8676.12304

Ticktin, M. (2014). Transnational Humanitarianism. Annu. Rev. Anthropol. 43, 273-289. doi:10.1146/annurev-anthro-102313-030403

Williams, S. A. (2010). Intersections of Accountability: Measuring the Effectiveness of International Development NGOs. Berkeley J. Sociol. 54, 27-58.

Witcher, A. (2020). Greece's Discriminatory Migrant Regime: Volunteers, Informal Street-Level Bureaucrats, and Moral Rationalities. J. Refugee Stud., 1-20. doi:10.1093/jrs/feaa083

Woods, K. (2019). "Refugees' Stories: Empathy, Agency, and Solidarity. J. Soc. Philos. 51 (4), 507-525. doi:10.1111/josp.12307

Conflict of Interest: The authors declare that the research was conducted in the absence of any commercial or financial relationships that could be construed as a potential conflict of interest.

Copyright (c) 2021 Shults, Haaland and Wallevik. This is an open-access article distributed under the terms of the Creative Commons Attribution License (CC BY). The use, distribution or reproduction in other forums is permitted, provided the original author(s) and the copyright owner(s) are credited and that the original publication in this journal is cited, in accordance with accepted academic practice. No use, distribution or reproduction is permitted which does not comply with these terms. 